Running head: sex, sexuality and gender role and interpersonal distance

\title{
The influence of biological sex, sexuality and gender role on interpersonal distance ${ }^{1}$
}

David Uzzell ${ }^{1}$, Nathalie Horne ${ }^{2}$,

${ }^{1}$ Department of Psychology, University of Surrey

${ }^{2}$ Research Support Unit, Greenwich, Lambeth, Lewisham \& Southwark PCT, London

${ }^{*}$ Requests for reprints should be addressed to Professor David Uzzell , Department of Psychology, University of Surrey, Guildford, Surrey, GU2 7XH, UK (e-mail: d.uzzell@surrey.ac.uk).

\footnotetext{
${ }^{1}$ Uzzell. D and Horne, N. (2006) The influence of biological sex, sexuality and gender role on interpersonal distance, British Journal of Social Psychology, 45, 579 - 597.
} 


\section{Abstract}

Changing cultural and societal attitudes towards homosexuality, gender stereotyping and gender roles in recent decades have prompted this study to re-examine the role of gender in spatial relationships and challenge previous research findings. This research reports on a conceptually and methodologically innovative study which sought to measure the influence of gender on interpersonal distance. Poor operational definitions and inadequate measurement methodologies have been the two principal shortcomings of research on personal space and interpersonal distance over the past 30 years. A new methodology the Digital Video Recording Interpersonal Distance Method (DiVRID) - involving high quality digital video equipment was devised for measuring interpersonal distance. Furthermore, whereas the distinction male/female has usually been employed for measuring 'sex' differences, this study differentiated between biological sex, gender role and gender identity. The importance of a more sophisticated conceptualization of gender has challenged the results of previous research, demonstrating that gender role accounts for more of the variation of IPD than the conventionally reported gender variable, sex.

\section{Introduction}

It is not difficult to appreciate why personal space as an area of research endeavor has assumed such significance and column inches in environmental and, to a lesser extent, social psychology text books and courses for the last 30 or 40 years. The way in which people interact with others using space as a means of managing their interpersonal spatial relationships, provides an immediate and salient example of spatial behavior. The importance of the socio-environmental context and contingencies that affect social interaction means that it is also highly relevant to our understanding of processes in social psychology (e.g. personal attraction, prejudice). In recent years, such research has been seen to have a practical utility. For example, in legal cases of sexual harassment spatial 
proximity can be a critical issue. Hern (1991) cites examples of judges specifying minimum distances between anti-abortion protesters and clients in demonstrations outside clinics.

Various labels have been given in the research literature to describe this area of human spatial behavior - personal space, proxemics, individual distance, interpersonal spacing, body-buffer zone, etc. In this paper we use the term interpersonal distance (IPD), not because we wish to add to the plethora of terms already employed, but this describes very concisely the focus of the human spatial behavior researched for this paper.

It is perhaps noteworthy that of the 1228 published papers, chapters or dissertations referenced between 1967 and 1997 under the keywords 'personal space' on the Psyclnfo database, $45 \%$ were published in the first decade, $37 \%$ in the second decade and only $18 \%$ between 1987-97. There has clearly been a decline in interest in personal space research. One possible reason for this is that while there was theoretical grounding to the some of the research, some environmental psychologists felt not wholly comfortable working within evolutionary and biological explanatory frameworks that were often used to account for human spatial behavior. Furthermore, there seemed to be no end of studies seeking to identify factors which might influence personal space, but for every variable identified as having an impact in one direction, another could be found that had a counter effect. Many research studies seemed to produce inconclusive findings, perhaps largely because the key variables involved were not properly operationalised. Indeed, as Sommer has recently written in his review of over 35 years of personal space research, "Problems of definition continue to trouble those who review research studies in this area. It seems less of a problem for researchers who employ operational definitions" (Sommer, 2002, p.656). This is none more so true than in studies seeking to measure the effect of gender on personal space. 
The application of clear operational definitions as well as the enhanced measurement accuracy offered by modern digital technologies which were not available two or three decades ago, suggest that the ambiguities of previous research can be overcome.

Furthermore, the relevance of this work has arguably increased in the light of changes in society and population sub-cultures, i.e., the more widespread acknowledgement and acceptance of 'gay culture' as well as gender issues. The results from this study, which uses an innovative and highly accurate methodology for plotting interpersonal distances, demonstrate that there are significant gender differences in interpersonal distances; furthermore, how one defines sex and gender also has a crucial effect on IPD results.

Gender has been one of the principal foci of IPD studies, but they have not been immune to some of the methodological shortcomings and difficulties identified here. Aiello (1987) carried out an extensive review of interpersonal distance studies and found that although many of the published papers found differences between males and females, there were many exceptions. Although the research results have been inconsistent, the general consensus in same-sex pairs is that male pairs maintain larger distances than female pairs at all ages (Aiello, 1987; Barnard \& Bell, 1982; Sussman \& Rosenfeld, 1982). Many studies have found that gender is not a powerful determinant on its own, but when interacting with other factors, e.g. race and age, it can become increasingly salient (Heckel \& Hiers, 1977; Severty, Forsyth \& Wagner, 1979). It has been suggested that these results may indicate socialization differences between men and women rather than a biological difference (Deaux \& LaFrance, 1998; De Paulo \& Freidman, 1998). The present study sought to address this problem by examining the effect of three different concepts of gender on spatial behavior. This research investigates the interpersonal distances employed by individuals to moderate interpersonal distancing, consciously or unconsciously, in relation to three different gender related variables; sex, sexuality and gender role. 
There is an increasing acceptance of a more liberal definition and interpretation of gender since the dynamics of gender roles are changing rapidly. Public expressions of homosexuality, the presence of less rigid gender stereotyping and changing attitudes towards gender roles in recent decades have prompted this study of the role of gender in spatial relationships.

\section{The Concept of Interpersonal Distance}

Explanations for variations in IPD can be characterized as having either focused on the function of space in mediating interpersonal relationships, or the mediating variables which influence IPD. There are three functional explanations of the variation of IPD between different kinds of people: i) Communication (Hall, 1959, 1963, 1966), i.e., the notion that IPD tells another person and onlookers information concerning the nature of the relationship between the individuals (e.g. can distinguish between intimate and public relations, but also closeness can be used to demonstrate affection for another); ii) Self-protection (Dosey \& Meisels, 1969; 1971), the idea that the greater the individual perceives risk to their emotions, physical being or privacy, the greater the interpersonal distance required to enable escape (Altman, 1975; Edney, Walker \& Jordan, 1976); iii) Arousal Regulation (Evans, 1974), i.e., by varying IPD, individuals can control the amount of sensory information they are receiving and avoid sensory overload which can lead to increased arousal and stress.

Previous research has tended to concentrate on the primacy of one approach over another. In this study, function is not treated as centrally critical. Since these functions are not mutually exclusive it seems appropriate to combine these ideas in order to understand and explore the differences in the way IPD is mediated by gender, where such differences may be a product of arousal regulation, communication and self-protection. In practice, these functions in an interpersonal situation may be difficult to disaggregate. 
Argyle and Dean (1965) constructed the Affiliative-Conflict Theory (also named the Equilibrium Theory) to account for this type of approach/retreat behavior. It suggests that each personal encounter involves approach and avoidance behaviors to achieve an optimal interpersonal distance. This was extended by Patterson (1976) who suggested that any adjustment in IPD by the active member is judged by the passive recipient as positive or negative. If judged positive, the new distance is maintained, and may even be exaggerated, however if judged negative, then the original comfort level is sought. Since this study concentrates on the effect of gender roles, which is likely to involve dominance and submissiveness as traits of masculinity and femininity (respectively), this theory is of particular relevance to this research.

Most studies which have sought to assess the factors which mediate IPD between participating actors have focused on gender and cultural differences. Other factors have included intrapersonal mediators such as age, attractiveness (Gifford, 1997), culture (Aiello, 1987), personality (Gifford, 1997), and disability (Eaton, Fuchs and Snook-Hill, 1998; Rapp \& Gutzmann, 2000) situational or contextual factors (Adams \& Zuckerman, 1991; Jain, 1993; Sinha \& Nayyar, 2000). An excellent overview of research on interpersonal and situational factors can be found in Sommer (2002). This study focuses on one mediating factor gender.

Previous research has generally concluded that same sex female pairs maintain closer distances than same sex male pairs (Aiello, 1987; Gifford, 1997). The distance between opposite sex pairs depends on familiarity and affiliation, and indeed may support closer distances than same sex pairs; it will depend, not surprisingly, on the relationship. It has been argued that this may be due to the stronger female socialization to be affiliative. However, the tendency for women to maintain closer distances does not hold in all situations - it can be mediated by other factors such as age and ethnicity which may counteract any 
affiliative norms. As Gifford argues 'gender is not simply as powerful a determinant of personal space, on its own, as are other variables' (Gifford, 1997, p.101).

\section{Gender Role \& Gender Role Reversal}

Institutional definitions and applications of gender related terms have been confused and inappropriate for operational research purposes. For example, the US Census Bureau (2000) defines sex as 'self-classification by gender, either male or female.' Furthermore, most of the research literature on IPD cited above dates from the 1970s and 1980s. Lesbian and gay culture has changed considerably since gender was used as a fairly simplistic measure of sex difference. The period since the 1980s has seen gender-focused groups striving for attention and acceptance and contesting the stereotypes that surround them. Gay and lesbian culture, while perhaps not mainstream, has asserted itself to such an extent that as an area of academic study it has its own journals and degree-bearing courses, while in public life anti-discriminatory measures are affirmed in both legislation and work practices.

By reflecting on the sociological and behavioral elements of the sexes that may have an influence on spatial behavior, distinctions arise that are no longer clearly defined by either biological categorizations (e.g. affection, tone of voice, aggression, competition), or socially constructed categorizations, (i.e. masculinity and femininity). As Bem (1993) argues, underlying both these biological and sociological constructions there has been an assumption of gender polarization. That is, masculinity and femininity were treated as 'states' occupying opposite ends of a bi-polar masculinity-femininity scale, however 'masculinity' and 'femininity' were constructed. Masculine and feminine were 'assumed to represent two fully independent scales of culturally defined masculinity and culturally defined femininity, respectively' (Bem, 1993, p119). The consequence of this is that an individual, rather than being classified at some point on a continuous scale from masculine to feminine, could now have attributes of both 
In this paper we have sought to distinguish between sex, gender role and gender identity.

a) Sex is the distinction between males and females based on the biological differences in sexual characteristics.

b) Gender role refers to an idiosyncratic cluster of personal characteristics that can be linked to gender (Spence, 1985). Therefore it is a label for the masculinity or femininity of someone's (social) behavior. In this paper it is measured by the Bem Sex Role Inventory.

c) Gender Identity is the personal identity of being male or female and is set in the individual's psychological relationship to gender in society (Sherif, 1980). For some persons such as transsexuals, there may be a discrepancy between their original biological sex and the sex they report themselves to be.

According to these definitions it is possible to be female, and identify oneself as a female (gender identity) and yet exhibit masculine characteristics and behavior (masculine gender role). In other words, following Bem, although both gender role and gender identity can be male or female they are, in fact, independent of each other. An individual may have the gender identity of one sex but exhibit the gender role of the other.

The issue of homosexuality has been related to gender role 'deviations'. As Al-Issa (1987) states, there is a tendency in homosexual gender issues toward gender role reversal. An influential study by Thompson, Schartz, McCandless and Edwards (1973), and similar research by Evans (1971) and Heilbrun and Thompson (1977) found that lesbians scored higher (i.e., more masculine) on the masculinity-femininity scale compared with their 'straight' ${ }^{2}$ controls, and gay men were less masculine and sometimes more feminine than controls. Ward (1974; cited in Spence \& Helmreich, 1978) also found that lesbians scored 
higher on masculinity and lower on femininity scales than the control groups. Oldham, Farnill and Ball (1982) used the Bem Sex Role Inventory (BSRI; Bem, 1974) to look exclusively at lesbians and again found similar results. However, because masculinity and femininity were treated as two independent constructs rather than a bipolar scale, the results can be presented in a way that may be more informative. They found that lesbians scored higher on the masculinity scale and yet showed no difference in the femininity characteristics than the straight control group. Bernard and Epstein, (1978) found that straight men scored higher on the masculine scores and gay men scored higher on the feminine scores.

The BSRI is the most widely used gender role measure and was used in this research to identify the gender roles of participants. It includes two scales; a masculinity scale and a femininity scale that were constructed specifically for the purpose of identifying individuals' gender roles as masculine, feminine or androgynous. This was achieved by assessing the differences between the subjects' endorsements of masculine or feminine characteristics. If the difference between the $\mathrm{m} / \mathrm{f}$ characteristics' endorsement is high the person is categorized as the gender-type with the highest score (i.e., masculine or feminine); if the difference is low, they are categorized as androgynous.

The BSRI has been extensively used, and hence its reliability and validity have been subject to considerable scrutiny yielding both confirmatory (e.g. Ballardreisch \& Elton, 1992; Blanchardfields, Suhrerroussel \& Hertzog, 1994; Campbell, Gillaspy \& Thompson, 1997) and more sceptical results (Hoffman \& Borders, 2001; Wilcox \& Francis, 1997). Much of the criticism of the scale has stemmed from disagreement with the principle of androgyny. As this has slowly become accepted, critics became more interested in the internal validity of the measure (e.g. Wilcox \& Francis, 1997). A factor analytical study by Campbell et al. (1997) found the short form of the inventory (i.e., the one used in this study) was more

\footnotetext{
${ }^{2}$ Following the growing convention in social psychology, we use the term 'straight' rather than heterosexual, in
} 
reliable than the longer form. Chung (1995) examined the construct validity of the BSRI for straight and gay men and found that it was valid for use with both groups of men. Concern more recently has looked at how the roles of men and women have changed since 1974 and whether Bem's measure is still valid. Holt, (1998) repeated Bem's method to categorize various adjectives and concluded that it is still a valid measure for assessing present gender roles although frequent revalidations would be warranted in the future.

\section{Research Question and Hypotheses}

The study reported in this paper investigated the relationship the degree to which interpersonal distances between men and women are a function of the three different gender related variables discussed above. Studies have looked at straight people's choice of IPD when interacting with a known lesbian or gay man (Gentry, 1988; Mooney, Cohn \& Swift, 1993), but there appears to be no research concerning the IPDs that lesbians and gay men use between themselves, i.e., research on IPD and sexuality and also gender role. Lesbians, gay men and bisexuals are ideal groups to investigate in this area due to their increased frequency of gender role reversal. Consequently, a sample was selected for this study with the expressed intention of measuring the impact of various of sexualities and concepts of sexuality on interpersonal distances.

The principal hypotheses investigated in this paper are:

$H_{1}$ - there will be a stronger correlation between gender role and IPD than biological sex and IPD

$\mathrm{H}_{2}$ - gender role will account for more of the IPD variance than biological sex

$\mathrm{H}_{3}$ - the IPD of masculine/masculine dyads will be greater than the IPD of feminine/feminine dyads.

contrast to gay/lesbian/bisexual. 
$\mathrm{H}_{4}$ - the IPD of Intermediate/Intermediate (i.e., middle of the sexuality range) dyads is expected to be different from the masculine/masculine dyads or feminine/feminine dyads.

Gender role reversal is also of interest in this research since the design is partly based on the assumption that this phenomenon will be less common in straight than in lesbian, gay and bisexual sexualities.

\section{Methodology}

Three principal methodologies have been employed to examine interpersonal variation in personal distances; projective, laboratory and observation. Projective techniques involve asking participants to hypothetically imagine a situation and indicate, either with pencil or paper or using dolls or figures, how they believe they or another individual would respond spatially in that scenario (e.g. Duke \& Nowicki, 1972; Gifford \& Price, 1979; Little, Ulehla \& Henderson, 1968; Summit, Westfall et al, 1992). Hayduk (1983), reviewing the studies using this technique, concluded that it is simply not credible. It has several obvious flaws such as requiring complex cognitive skills like re-construction, imagination, empathy, memory demands, and most difficult of all, re-scaling from life size to the perceived scale of the figures. These shortcomings are overcome in part by other methodologies, but these in turn have other deficiencies.

Laboratory measures have been also widely used (e.g. Dosey \& Meisels, 1969; King, 1966; Kunzendorf \& Denney, 1982). As with projective measures, they are simple to administer and interpret. The most common laboratory method is the 'stop-distance' method, which asks one participant to enter a room and continue to approach another until the point when they start to feel uncomfortable with the other's proximity. Alternatively, 'approach distance' is used in which subjects are asked to move towards another person(s) or person surrogate (e.g., a photograph of different types of people) and indicate at which point they cease to feel 
comfortable. The advantage of these techniques compared with the projective methodology, is that it is undertaken with human beings who can monitor their own feelings and behavior. Although conducted in a laboratory it is not too difficult to contrive the setting so that it might approximate say, an office, and so the experiment can have some degree of ecological validity. However, accurate measurements are difficult, as participants are asked to use their own bodies to position themselves according to hypothetical situations.

The third methodology is observation. This is by far the most desirable, but also entails the most practical difficulties (e.g. Jorgenson, 1975; White 1975), not least of which in terms of accurate measurement. It involves direct observation of people interacting with each other in real situations and preferably by unobtrusive means. There are two types of observation which are unobtrusive and field-based: a) unstructured, which is largely a naturalistic, unobtrusive and uncontrolled observation, and reflects people interacting in a real world setting, b) staged invasions or blocked access in natural settings; in both situations either unwitting subjects are approached by a confederate or the path of people are blocked by confederates and the reactions monitored

Each of these methodologies has strengths, but they also have many weaknesses. It has to be remembered, however, that while all of these techniques come under the heading of IPD or personal space, they can have slightly different goals. For example, in the case of the field experiments one may be interested simply in types of behavioral response, not the actual and accurate interpersonal distance between subjects. Balancing ecological validity with accuracy of measurement is probably the most problematic issue. We made the judgment that accuracy of measurement is a critical criteria as variations in interpersonal distances are likely to be extremely small and subtle. Although the design of this research has taken into account the limitations of these methodological issues (e.g., suggestibility and intrusiveness are avoided) and incorporate the better features of previously employed 
methodologies (e.g., direct observation), it was felt that a new methodology should be devised in which accuracy of measurement takes priority and allowing for the measurement of IPD as a sub-conscious behavior. It is noteworthy that since the majority of research on interpersonal distances was undertaken in the 1970s and 1980s, there have been considerable technological advances in digital technology, especially in the use of digital video recording equipment, which permits highly accurate measurements of recorded distances.

\section{Digital Video Recording Interpersonal Distance Method (DiVRID)}

The observation was structured and conducted in a laboratory setting so that consent could be obtained and interactions could be controlled and accurately recorded. There were two forms of measures used; one measured the interpersonal distance of each dyad, and the other was a pre-tested measure of each participant's gender role.

The laboratory was laid out as in Figure 1. Three equally spread measurement mats known to the participants as 'Stations A, B \& C' were laid on the floor. These were an integral part of the means by which accurate measurements of interpersonal distances could be recorded. Each mat was $0.89 \mathrm{~m} \times 1.60 \mathrm{~m}$ and made from cream colored, durable plastic sheeting marked in black with a grid of 1" $x 1$ " squares. Distances were subsequently converted into centimeters for data analysis and presentation. A video camera was placed 3 meters from the near edge of each mat on tripods and at a height of 2.5 meters. The cameras were positioned so that only the measurement mats filled the frame.

\section{[FIGURE 1 ABOUT HERE]}

In order to test the influence of biological sex, sexuality and gender role on interpersonal distance the study focused on dyads as the unit of analysis. This was achieved by conducting the experiment in groups of six participants so that each participant interacted 
with each of the other five participants in the group of varying gender characteristics.

Therefore, each participant was associated with five IPD measurements for interactions with five different people. Twelve sessions with 6 participants in each yielded 180 dyad trials in total.

The distances between dyads were measured using a high quality digital video cameras setup (DiVRID); the grid on the mat enabled highly accurate measures to be taken of interpersonal distance. Measurements were taken from the mid-point between participant A's feet to mid-point between participant B's feet as illustrated in figure 2. The video tapes were analyzed using a 15-second interval observational recording method.

\section{[FIGURE 2 ABOUT HERE]}

\section{Participants}

The authors were very alert to the various sampling problems of through heterosexual bias as identified by Herek et al (1991). These included not confusing sexual orientation with gender identity and gender role conformity, as well as perhaps one of the principal problems in this area of work, ensuring that the sample is representative. Lesbian, gay and bisexuals, notwithstanding cultural and societal changes over the last decade or so, are still a stigmatized group and so, as with any social stigma, an unknown proportion of the population will not disclose. Consequently, it is difficult to know what the population is from which one is hoping to draw a representative sample.

The sample comprised 72 university students from the University of Sussex, England. A university sample was seen as appropriate; first, it offered a better opportunity for recruiting participants of varying sexualities and therefore increased the chance of achieving more diversity in gender role reversal. Second, it was thought that students at university may be 
more accustomed to the non-heterosexual sexualities and therefore would be more at ease, and that homophobia may be less influential as a confounding variable. The sample was drawn by two means. Participants were randomly recruited by approaching students outside the students union on the University campus. The University of Sussex has an active Lesbian, Gay, Bisexual, and Transsexual Society (LGBT), and members were approached, with the co-operation of its officers, by email. LGBT members were asked to participate in a study as a favor for 'a friend' so that they did not believe they were selected because of their membership of the society or their sexuality. All other participants were recruited simply by asking them as they walked past the student's union. Students were only approached if they appeared to be approximately 18-26 years of age, of white ethnicity and seemed to be UK nationals.

Of the 72 participants, 34 (47\%) were males and 38 (53\%) females, with ages ranging from 17 to 31 with a mean age of 21.2 years. Just under $90 \%$ of the female sample $(n=33)$ said they were straight, four were lesbians and one was a bisexual. Of the male sample, 25 (74\%) said that they were straight, eight were gay men, and one was a bisexual. The majority of the participants (89\%) were from the UK and all participants were white adults. 


\section{Measures}

The Bem Sex Role Inventory (BSRI; Bem, 1974) comprises sixty adjectives against which participants indicate on a seven point Likert scale how well it describes them (1 never/almost never true; 2 - usually not true, 3 - sometimes but infrequently true, 4 occasionally true, 5 - often true, 6 - usually true, 7 - always or almost always true). Twenty of the adjectives constitute the masculine measure and a second twenty constitute the feminine measure. The remaining twenty adjectives are neutral and are not included in the final calculations. The resulting BSRI score identifies the participant on a scale from very masculine to very feminine; with androgynous as a narrow band of scores in the middle.

In the same questionnaire, there were four demographic questions asking about the participant's sex, age, nationality and sexuality (straight/gay/bisexual). They were also asked whether they knew any of the other participants within the experimental session.

\section{Procedure}

Each session of the experiment consisted of six participants, randomly compiled, of a variety of sexes, sexualities and gender roles. Participants were lead to the laboratory situated within the Students' Union. The laboratory was approximately $11.5 \mathrm{~m} \times 10.5 \mathrm{~m}$ with a ceiling height of $4 \mathrm{~m}$. Initially participants were given to understand that their participation was required for a psychology research project concerning memory and their ability to remember facts about other people to whom they had spoken.

On entering the laboratory participants were briefed that the purpose of the study was to talk to each of the other five people, and asking prompt questions displayed on the poster at either end of the room (these were positioned to encourage the interacting participants to orientate themselves at $90^{\circ}$ to the camera). The questions were their other's name, age, mother's name, father's name, what time they woke up, what they had for breakfast, and 
brothers' and sisters' names and ages. They were asked to remember what they could about each person in the two minutes they were allocated, using whatever mechanisms they felt necessary. They were also informed that they would be asked to complete a short questionnaire afterwards. They were told that the experiment would be video recorded for future analysis, should it be required.

Participants were given a badge randomly numbered between 1 and 6 and asked to go to their first station as instructed by the experimenter. They were reminded that they should remain at each station for the full two minutes, rehearsing the information if necessary. After the first interaction trial, the experimenter indicated that they should stop talking and move on to the next interaction, which was indicated by the researcher. This was repeated until all participants had spoken to each other (for order of dyads, see Table 1).

\section{[TABLE 1 ABOUT HERE]}

Participants were then given a questionnaire marked with their badge number and session number and were reminded of the confidentiality of the data collected. Once all the questionnaires were completed, participants were debriefed as to the true purpose of the study and given the opportunity to ask questions; they were also given the opportunity to withdraw their contribution to the experiment should they wish. No participants indicated that they wished to withdraw their participation. Each group was also asked if they had any suspicions that their interpersonal distance was being measured; none had.

\section{Results}

The analysis examined interpersonal distance and its relationship with three sex related variables (sex, sexuality, and BSRI score). Relationships between the three gender-related variables were also examined. There was no significant differences in IPD between dyads 
that knew each other and those that did not $(t(178)=-1.62, p=n . s$.$) . Therefore it was not$ necessary to account for this factor in any further analysis. Descriptive statistics of the Interpersonal distance measurements according to the categorization of the three variables can be seen in Table 2 .

[TABLE 2 ABOUT HERE]

\section{Categorization of BSRI scores}

The BSRI scores are typically categorized into three groups. Bem's scoring is calculated on the basis that the androgynous group is defined "on the basis of their femininity minus masculinity difference score, with a small difference scores indicating androgyny and large different score is indicating either sex typing or cross sex typing" (Bem, 1993, p120). The BSRI defines androgynous people as having an index score of between -1 and +1 , while masculine and feminine individuals fall outside this range (i.e., masculine $<-1$; feminine $>1$ ). We accept Bem's argument that an individual can have attributes of both masculinity and femininity and therefore masculinity-femininity is not a continuous uni-dimensional scale, and we were concerned to reflect this in our measurement instrument of gender. Thus respondents were given the two scales to complete and their score involved subtracting their masculinity score from their femininity score. As androgyny was not of central interest to us we felt less duty bound to fulfill the strictures of Bem's criteria for the measurement of androgyny ${ }^{3}$. Hence, we employed a wider band for comparison between groups.

Categories were formed by dividing the entire population $(n=72)$ into three equal groups according to the range of BSRI scores. Therefore the most masculine group included participants with BSRI -11.61, the middle group included participants with $11.61>\mathrm{BSR} \leq 14.36$ and the most feminine group included participants with BSRI>14.36. Therefore the group who were high in masculinity were participants with BSRI scores $\leq$ -

\footnotetext{
${ }^{3}$ Only 2 participants within this sample fell within the range of $-1 /+1$.
} 
11.61, the Intermediate group included participants with $-11.61>B S R I \leq 14.36$ while the group most high in femininity included participants with $B S R I>14.36$. The middle group was called Intermediate, and not 'androgynous' since it included participants with masculine or feminine scores according to the BSRI, yet were not as extreme as participants from the other two groups. When converted into dyads, six groups were formed: 1- masculine/masculine; 2 masculine/Intermediate; 3 - masculine/feminine; 4 - Intermediate/Intermediate; 5 Intermediate/feminine; 6 - feminine/feminine.

\section{$\underline{\text { Relationships between Sex, Sexuality and Gender Role }}$}

Figure 3 shows the configuration of participants' sexualities within the three BSRI categories. The masculine and feminine categories contain approximately $75 \%$ of males and females respectively, and therefore the remaining $25 \%$ demonstrate gender role reversal. The Intermediate category contains similar numbers of straight males and females, $50 \%$ of the lesbians, but very few gay men in comparison with the other two categories. Thus the three categories contain both males and females and are structurally different to groups that are differentiated by biological sex.

\section{[FIGURE 3 ABOUT HERE]}

There was a main effect of sex on BSRI scores $(F(1,70)=14.70, p<.01)$ and a main effect of sexuality on BSRI scores $(F(4,67)=5.59, p<.05)$, the only significant difference being between straight males and straight females. 
The first hypothesis $\left(\mathrm{H}_{1}\right)$ was that there will be a stronger correlation ${ }^{4}$ between gender role and IPD than biological sex and IPD. This hypothesis was supported $(t=-1.61, d f=173, p$ $=0.05$ ); the correlation matrix (Table 3 ) reveals that of the three gender-related variables, the BSRI has the strongest correlation with interpersonal distance $\left(r_{s}=-.39, n=72, p<.01\right)$ followed by sexuality $\left(r_{s}=-.29, n=72, p<.01\right)$; the weakest correlation is with biological sex $\left(r_{s}=-.21, n=72, p<.01\right)$. It is noteworthy that the correlation between sex and BSRI is not stronger $\left(r_{s}=.41, n=72, p<.01\right)$, emphasizing the importance in distinguishing between them.

The second hypothesis $\left(\mathrm{H}_{2}\right)$ predicted that gender role will account for more of the IPD variance than biological sex. This hypothesis was also supported; the correlation between BSRI and sexuality is higher $\left(r_{s}=.52, \mathrm{n}=72, \mathrm{p}<.01\right)$ than BSRI and sex $\left(r_{s}=.41, \mathrm{n}=72\right.$, $\mathrm{p}<.01)$.

The third hypothesis $\left(\mathrm{H}_{3}\right)$ predicted that the IPD of masculine/masculine dyads will be greater than the IPD of feminine/feminine dyads. A one-way $\mathrm{ANOVA}^{5}$ found a significant main effect of the dyad's sexuality on IPD $(F(9,167)=3.43 ; p<.05)$. A Post-Hoc analysis identified that straight female/straight female dyads differed significantly from straight male/lesbian dyads and also from straight male/straight female dyads $(p<.05)$ in IPD. This again demonstrates the difference in IPD between sexualities within the sexes. A Factorial ANOVA identified a main effect of the dyad's BSRI combination, $(F(5,163)=3.92 ; p<.05)$,

\footnotetext{
${ }^{4}$ The reason $r s \neq 1.00$ is that the bisexual men and women were amalgamated for the purpose of this correlation matrix, otherwise the bisexual male and bisexual female groups would have been too small.

${ }^{5}$ This factor was dealt with separately because some of the groups had fewer than two cases and therefore a factorial ANOVA was not possible. Three groups had only one case, and were therefore removed for the purpose of this analysis only (gay/gay; gay/bisexual; and lesbian/lesbian).
} 
but no main effect for the dyad's sex combination, nor a significant interaction. Further analysis shows where differences in means lie between the dyads (Table 4).

\section{[TABLE 4 ABOUT HERE]}

The final hypothesis $\left(\mathrm{H}_{4}\right)$ was that the IPD of Intermediate/Intermediate (i.e., middle of the sexuality range) dyads will be different from the masculine/masculine dyads or feminine/feminine dyads. This hypothesis was not supported. The Intermediate/Intermediate dyad is the only dyad that does not differ significantly from any other dyad. These results are graphically displayed in the box-plot in Figure 4.

\section{[FIGURE 4 ABOUT HERE]}

\section{Discussion}

The results show no effect of sex on IPD. There was, however, an effect of gender role on IPD. Certain combinations of BSRI scoring dyads differed significantly from each other and it can therefore be asserted that this particular difference in interpersonal distance may be due to their gender roles.

In support of the principal hypothesis, there was a much stronger correlation between gender role and IPD than between biological sex and IPD. It is interesting to note that even participants' sexualities correlated more strongly with IPD than their biological sex.

As predicted in the third hypothesis, the masculine/masculine dyads demonstrated larger IPD than the feminine/feminine dyads. Furthermore, significant differences occurred between dyads, which were formed of at least one of the more masculine of participants, and dyads that involved none of the more masculine participants. 
The fourth hypothesis predicted that the Intermediate group would differ significantly from the masculine/masculine and the feminine/feminine dyads. This was not, however, upheld. This was probably because the Intermediate group was not truly androgynous, but also incorporated some of the masculine and feminine participants who scored low on the BSRI index. Due to the very narrow band that defines androgyny in the BSRI scale, the sample drawn in this study would not allow such sensitivity of measurement; differences may be significant in a much larger sample. Nonetheless, the assumption behind the formulation of this hypothesis seems justifiable since the mean IPD for the Intermediate/Intermediate group lay almost exactly in-between the mean IPDs for the masculine/masculine and feminine/feminine dyads.

Of all these findings, the most significant is that of the relationship between gender role and IPD. It would seem, as has been suggested by Deaux and LaFrance (1998) and De Paulo and Friedman (1998) that the influence of socialization can account for more of the variation in IPD (and perhaps other non-verbal behaviors) than the influence of biological sex. In looking at how gender can affect interpersonal interaction, the search for a difference in sex is superseded by the search for an understanding of the many dimensions of the communication processes such as balance of power and gender expectancies.

It is particularly interesting that differences in IPD between gender role dyads occurred between dyads that included at least one masculine participant and dyads that did not include any masculine participants. This could indicate that masculine people tend to control the interactions more and maintain a larger distance than feminine people. According to Argyle and Dean's (1965) and Patterson's $(1976,1977)$ extension to the theory of approach and avoidance, it would seem reasonable that the participant requiring a larger IPD would maintain this larger distance since neither party would then feel threatened (providing the 
distance is not too large). In other words, if a very masculine person (requiring a large IPD) is interacting with a person that is not very masculine (requiring a smaller IPD), then the masculine person's IPD is more likely to be maintained since the larger distance would not cause feelings of intrusion in the other person. This model is supported by the data.

The average IPD used by a dyad involving a masculine person was significantly different to almost any other dyad that did not include a masculine person (except for a dyad involving two people that are in the middle of the range of BSRI scores). If it were simply an issue of controlling influence, and feminine people were controlling smaller distances, then the feminine/feminine \& masculine/feminine combination would be expected to show similar distances, rather than the significant difference that was found. It is for this reason that it is suggested that the masculine participants were more influential in interactions than the feminine participants since their preference for significantly larger IPDs were granted. This conclusion is similar to that made by Sayers, Baucom and Tierney (1993) who discovered that high masculinity rather than sex predicted who was more convincing in a verbal dyadic situation. Weitz (1976) also concluded that the more submissive participants (women and feminine people) adjusted their non-verbal communications to fit the more dominant (male or masculine people).

It is fruitful to draw attention in this context to the work that has been conducted on personality types. Bearing in mind that participants were assigned to categories according to their scores on the BSRI it is instructive to have an understanding of some of the specific items on the questionnaire to which these groups of participants were responding. Masculine participants thought that the following adjectives described their characteristics most frequently; assertive, strong personality, forceful, leadership abilities, dominant, aggressive, competitive; whereas examples of the adjectives that the feminine participants scored highest on were; shy, affectionate, loyal, sensitive to needs of others, soft-spoken, 
warm, childlike, gentle. Research on authoritarianism (Frankel and Barrett, 1971), and aggression (Kinzel, 1970), for example, would have predicted similar results based on these different scales. The classification into masculine and feminine therefore clusters these personality characteristics together; this is ultimately the essence of gender role.

The results of this study obviously rely heavily on the validity of the gender role measure (BSRI). Pillard (1991) reviewed a collection of approximately 30 studies, the majority of which indicated that homosexual adults are gender atypical. An alternative interpretation of these results is that gay men simply respond to the BSRI measures in a similar manner to the majority of straight females, and that lesbians respond in a similar fashion to straight males. In other words, people that respond to the BSRI in a particular way exhibit larger IPDs than people that respond in another way, but that these two groups of people should not necessarily be labeled masculine or feminine. As Deaux and LaFrance (1998) note, the terms masculine and feminine will conjure up particular social representations, but one's own gender role is defined in more idiosyncratic terms and therefore Pillard's notion should not be so easily dismissed. Pillard acknowledges the utility of these measures, but suggests that great caution should be attached to their interpretation. Despite these limitations, this is how gender role is currently operationalized, and will continue to be so until an alternative measure is created.

These findings make an innovative contribution to the knowledge base surrounding human spatial behavior, and indeed other social and environmental psychological research, by broadening the boundaries between male and female characteristics. This research would suggest that biological sex is perhaps not the only important gender variable to consider when looking at interpersonal distances. With better access to a larger sample of lesbians, gay men and bisexuals, it would be interesting to focus more directly on the IPD between lesbians, gay men and bisexual and with straight people. The biased sample issue 
mentioned above would then not be a problem since the investigation would not be comparing the effects of biological sex.

The importance of a more sophisticated conceptualization of gender has challenged the results of previous research. One suspects that other areas of IPD research could well pay re-examination with the employment of the Digital Video Recording Interpersonal Distance (DiVRID) methodology. This study has demonstrated that as a consequence of a more sophisticated and subtle approach to the measurement of the independent variables by which variation in IPD we now have more subtle appreciation and understanding of human spatial behaviour. Of course, gender is not the only area to have experienced a cultural shift in the way in which it has been interpreted and employed over the last two or more decades. It now remains for other areas that were investigated in the 1980s and before to be reexamined in the light of changing societal attitudes and values as well as advances in social and environmental psychology; one immediately thinks of 'ethnicity', 'culture' and as examples of factors seen to influence IPD but for which ambiguous if not contradictory results have been found.

This research study is also significant in that it has developed and tested a new methodology (DiVRID) to examine IPD with a level of accuracy not hitherto achieved. Differences between individuals and groups in IPD are likely to be small. Small interpersonal distances may, however, be socially significant and therefore an accurate measurement instrument is critical.

Another feature that makes this research distinctive compared with earlier research is that it accounts for variation on several variables for both individuals of the dyads rather than keeping one participant constant (usually the experimenter). This methodological design does complicate data analysis in comparison to previous studies, but with this is gained a 
more comprehensive and ecologically valid understanding of interactions between different people rather than between one person and all the participants.

The issue of sexuality has been demonstrated to be of increased importance as a result of this research. Conclusions from earlier research concerning participants' sex and the relationships between them may have some connection with sexual attraction/difference, yet this is based on an assumption of heterosexuality, which in the modern world is unsustainable. Though professed lesbians, gay men and bisexuals may be in a minority, their numbers are still sufficient to make a difference. And, of course, there is still a stigma surrounding homosexuality and some will not 'come out' publicly; they would claim they are straight, but their gender role and possibly IPD may be more consistent to that of a homosexual than of a straight person.

The fact that there is a good correlation between BSRI and sexuality, which in fact was stronger than that with biological sex, would suggest that the BSRI is suited to the research of gender roles of lesbians, gay men and bisexuals. Although the issue of gender role reversal is not of direct interest, there is a suggestion that gender role reversal is more frequent in lesbians, gay men and bisexuals. Unfortunately, the sub-sample size does not permit the testing of this. It would be worthy of further research as it adds some support to findings of a higher incidence of gender role reversal in lesbians, gay men, and bisexuals (Bernard and Epstein, 1978; Oldham et al., 1982; Heilbrun and Thompson, 1977).

Finally, this study demonstrates that it is essential to distinguish between biological sex, sexuality and gender role and their influence on IPD, since it is evident that that gender role accounts for more of the variation of IPD than the conventionally reported gender variable, sex. When investigating IPD in the future it may be more important to control for the gender roles of the participants as well as their biological sex. 


\section{References}

Adams, L. \& Zuckerman, D. (1991). The effect of lighting condition on personal space requirements. Journal of General Psychology, 118 (4), 335-340.

Aiello, J. R. (1987). Human Spatial Behavior. In Stokols, D. \& Altman, I. (Eds.), Handbook of Environmental Psychology (Vol. 1). New York: Wiley

Altman, I. (1975). The Environment and Social Behavior: Privacy, Personal Space, Territoriality, Crowding. Monterey, CA: Brooks/Cole.

Argyle, M. \& Dean, J. (1965). Eye contact, distance, and affiliation. Sociometry, 28, 289-304.

Ballardreisch, D., \& Elton, M. (1992). Gender orientation and the Bem Sex-Role Inventory A Psychological Construct revisited. Sex Roles, 27, 291-306.

Barnard, W.A., \& Bell, P.A. (1982). An unobtrusive apparatus for measuring interpersonal distance. Journal of General Psychology, 107, 85-90.

Bell, P.A., Kline, L.M. and Barnard, W.A (1988). 'Friendship and freedom of movement as moderators of sex differences in interpersonal spacing', Journal of Social Psychology, 128, $305-310$.

Bem, S. L. (1974). The measurement of psychological androgyny. Journal of Consulting and Clinical Psychology, 42, 155-162.

Bem, S. L. (1993). The lenses of gender, New Haven: Yale University Press.

Bernard, L. C. \& Epstein, D. J. (1978). Androgyny scores of matched homosexual and heterosexual males. Journal of Homosexuality, 4, 169-178.

Blanchardfields, F., Suhrerroussel, L., \& Hertzog, C. (1994). A confirmatory factor-analysis of the Bem Sex-Role Inventory - old questions, new answers. Sex Roles, 30, 423-457.

Campbell, T., Gillaspy, J. A., \& Thompson, B. (1997). The factor structure of the Ben SexRole Inventory (BSRI): Confirmatory analysis of long and short forms. Educational and Psychological Measurement, 57, 118-124.

Chung, Y. B. (1995). The construct validity of the Be, Sex-Role Inventory for heterosexual and gay men. Journal of Homosexuality, 30, 87-97. 
Deaux, K. K., \& LaFrance, M. (1998). Gender. In D.T. Gilbert, S. Fiske, \& G. Lindsay (Eds.), The Handbook of Social Psychology (Vol. I, $4^{\text {th }}$ Ed., pp. 788-827). New York: McGraw Hill.

DePaulo, B. \& Friedman, H. (1998). Nonverbal communication. In D.T. Gilbert, S. Fiske, \& G. Lindsay (Eds.), The Handbook of Social Psychology (Vol. II, $4^{\text {th }}$ Ed., pp. 3-39). New York: McGraw Hill.

Dosey, M. A., \& Meisels, M. (1969). Personal space and self-protection. Journal of Personality and Social Psychology, 11(2), 93-97.

Dosey, M. A., \& Meisels, M. (1971). Personal Space, anger-arousal, and psychological defence. Journal of Personality, 39, 333-344.

Duke, M. P., \& Nowicki, S. (1972). A new measure and social learning model for interpersonal distance. Journal of Experimental Research in Personality, 6, 119-132.

Eaton, S.B., , Fuchs, L.S. and Snook-Hill, M. (1998). ' Personal space preference among male elementary and high school students with and without visual impairments'. Journal of Visual Impairments and Blindness, 92, 769-782

Edney, J. J., Walker, C. A. \& Jordan, N. L. (1976). Is there reactance in personal space? Journal of Social Psychology, 100, 207-217.

Evans, G. W. (1974). An examination of the information overload mechanism of personal space. Man-environment Systems, 4, 61.

Evans, R. B. (1971). Adjective Check List score of homosexual men. Journal of Personality Assessment, 35, 344-349.

Frankel, A. S. \& Barrett, J. (1971). Variations in personal space as a function of authoritarianism, self-esteem and racial characteristics of a stimulus situation. Journal of Consulting and Clinical Psychology, 37, 95-98.

Gentry, C. S. (1988). Development of scales measuring social distance toward male and female homosexuals. Journal of Homosexuality, 13(1), 75-82 
Gifford, R. (1997) Environmental Psychology: Principles and Practice, Boston: Allyn and Bacon

Gifford, R., \& Price, J. (1979). Personal space in nursery school children. Canadian Journal of Behavioral Science, 11, 318-326.

Hall, E.T. (1959). The silent language. New York: Doubleday.

Hall, E.T. (1963). A system for the notion of proxemic behavior. American Anthropologist, 65, 1003-1026.

Hall, E. T. (1966). The Hidden Dimension. New York: Doubleday.

Hayduk, L. A. (1983). Personal space: Where we now stand. Psychological Bulletin, 94, 293335.

Heckel, R.V. \& Hiers, J. M. (1977). Social distance and locus of control. Journal of Clinical Psychology, 33, 469-471.

Heilbrun, A. B., \& Thompson, N. L. (1977). Sex-role identity and male and female homosexuality. Sex Roles, 3, 65-79.

Herek, G.M., Kimmel, D.C., Amaro, H. and Melton, G.B. (1991). 'Avoiding heterosexual bias in psychological research', American Psychologist, 46, 9, 957-963.

Hern, W.M. (1991). Proxemics: the application of theory to conflict arising from antiabortion demonstrations, Population and Environment, 12, 379 - 388.

Hoffman, R. M., \& Borders, L.D. (2001). Twenty-five years after the Bem Sex-Role Inventory: A reassessment and new issues regarding classification variability. Measurement and Evaluation in Counseling and Development, 34, 39-55.

Holt, C. L. (1998). Assessing the current validity of the Bem Sex-Role Inventory. Sex Roles, 39, 929-941.

Jain, U. (1993). Concomitants of population density in India. Journal of Social Psychology, 133, 331-336.

Jorgenson, D. O. (1975). Field study of the relationship between status discrepancy and proxemic behavior. Journal of Social Psychology, 97, 173-179. 
King, M. G. (1966). Interpersonal relations in preschool children and average approach distance. Journal of Genetic Psychology, 109, 109-116.

Kinzel, A. F. (1970). Body-buffer zone in violent prisoners. American Journal of Psychiatry, $127(1), 59-64$.

Kunzendorf, R. G., \& Denney, J. (1982). Definitions of personal space: smokers versus nonsmokers. Psychological Reports, 50(3), 818.

Little, K. B. (1965). Personal Space. Journal of Experimental Social Psychology, 1, 237-247.

Little, K. B., Ulehla, Z. J., \& Henderson, C. (1968). Value congruence and interaction distances. Journal of Social Psychology, 75, 249-253.

Mooney, K. M., Cohn, E. S., \& Swift, M. B. (1993). Physical distance and AIDS: Too close for comfort? Journal of Applied Social Psychology, 22(18), 1442-1452.

Oldham, S., Farnill, D., Ball, I. (1982). Sex-role identity of female homosexuals, Journal of Homosexuality, 8(1) 41-46.

Patterson, M. L. (1976). An arousal model of interpersonal intimacy. Psychological Review, 83, 231-249.

Pillard, R. C. (1991). Masculinity and femininity in homosexuality: "Inversion" revisited. In J. C. Gonsiorek, \& J. D. Weinrich, (Eds.). Homosexuality: Research Implications for public policy. (pp.32-43). USA: Sage Publications Inc.

Sayers, S. L., Baucom, D. H., \& Tierney, A. M. (1993). Sex roles, interpersonal control and depression: Who can get their way? Journal of Research in Personality, 27, 377-395.

Severty, L. J., Forsyth, D. R. \& Wagner, P. J. (1979). A multi-method assessment of personal space development in female and male, black and white children. Journal of Nonverbal Behavior, 4, 68-86.

Sherif, C. W. (1980). Needed concepts in the study of gender identity. Presidential address, American Psychological Association, Montreal, Canada, September 1980. 
Sinha, S. P., \& Nayyar, P. (2001). Crowding effects of density and personal space requirements among older people: The impact of self-control and social support. Journal of Social Psychology, 140(16), 721-728.

Skorjanc, A. D. (1991). Differences in interpersonal distance among non-offenders as a function of perceived violence of offenders. Perceptual and Motor Skills, 73, 659-662.

Sommer, R. (1969). Personal Space. The Behavioral Basis of Design. Englewood Cliffs, NJ: Prentice-Hall.

Sommer, R (2002). "From personal space to cyberspace', in R..B. Bechtel and A Churchman (eds) Handbook of Environmental Psychology (pp. 647 - 660), New York: Wiley.

Spence, J. T. (1985). Gender identity and implications for concepts of masculinity and femininity. In T. B. Sondereggr (Ed.), Nebraska symposium on motivation: Psychology and gender (Vol. 32, pp. 59-96). Lincoln: University of Nebraska Press.

Spence, J. T., \& Helmreich, R. L. (1978). Masculinity \& Femininity. Austin: Univ. of Texas Press.

Summit, J.E., Westfall, S.C., Sommer, R. and Harrison A.A. (1992). 'Weightless and interaction distance', Environment and Behavior, 24, 617-633

Sussman, N. M. \& Rosenfeld, H. M. (1982). Touch, justification, and sex: Influence on the aversiveness of spatial violations. Journal of Social Psychology, 106, 215-225.

Thompson, N. L., Schartz, D. M., McCandless, B. R. \& Edwards, D. A. (1973). Parent-child relationships and sexual identity in male and female homosexuals and heterosexuals. Journal of Consulting and Clinical Psychology, 41, 120-127.

U.S. Census Bureau, (2000) Census of Population, Profiles of General Demographic Characteristics, Washington DC.

Weitz, S. (1976). Sex differences in non-verbal communication. Sex Roles, 2, 175-184.

White, M. J. (1975). Interpersonal distance as affected by room size, status and sex. Journal of Social Psychology, 95, 241-249. 
Wilcox, C. \& Francis, L. J. (1997). Beyond gender stereotyping: Examining the validity of the Bem Sex-Role Inventory among 16- to 19-year old females in England. Personality and Individual Differences, 23, 9-13. 
Figure 1. Illustration of the layout of the laboratory.

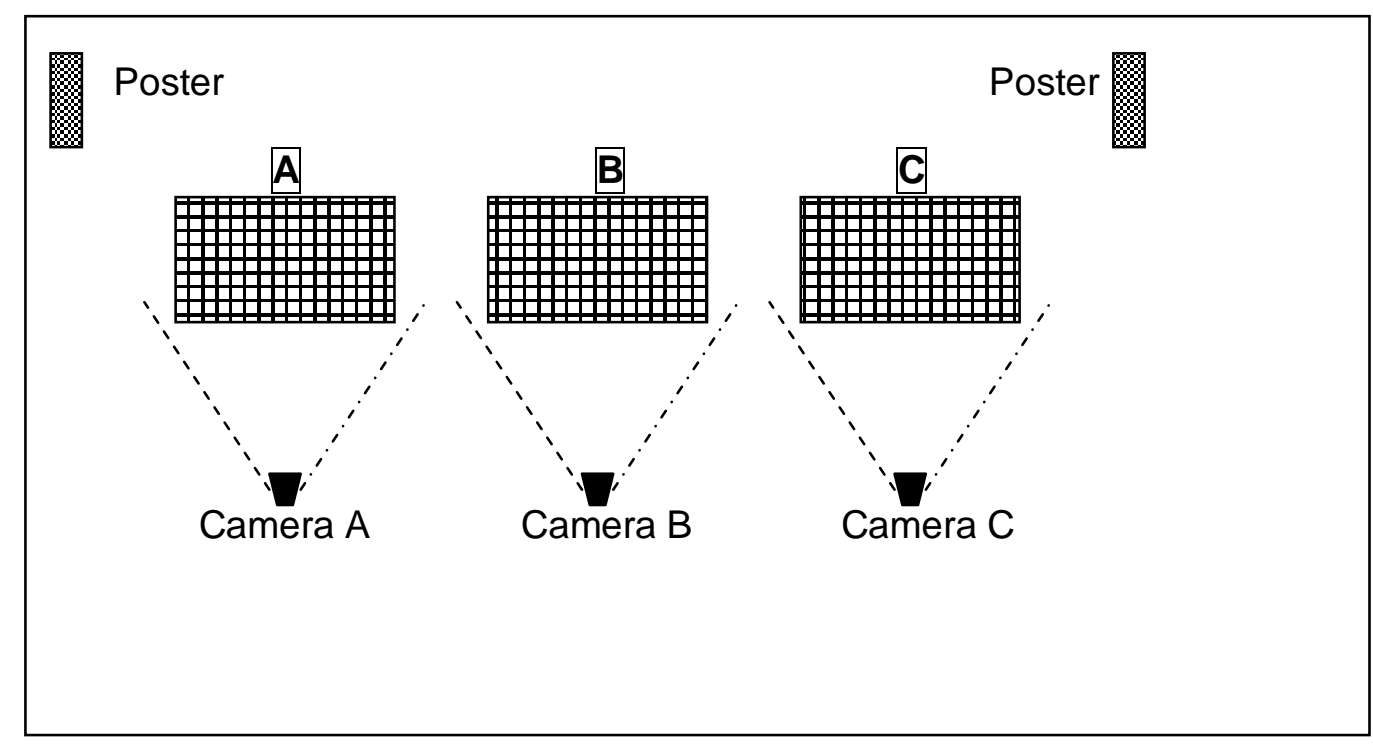


Figure 2. Illustration of measurement method between participant 1 and 2's feet

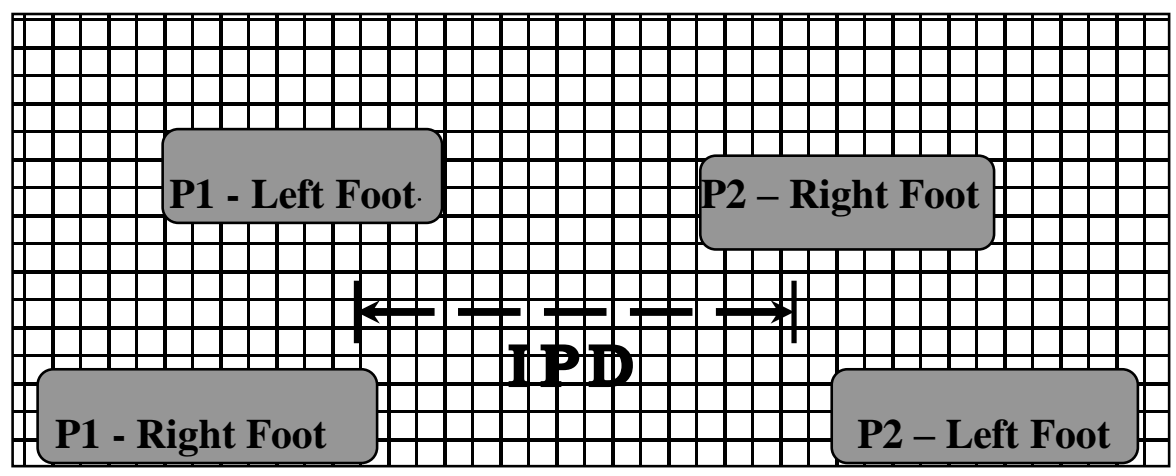


FIGURE 3 - Percentage bar charts showing the distribution of the sexualities within the three BSRI categories.

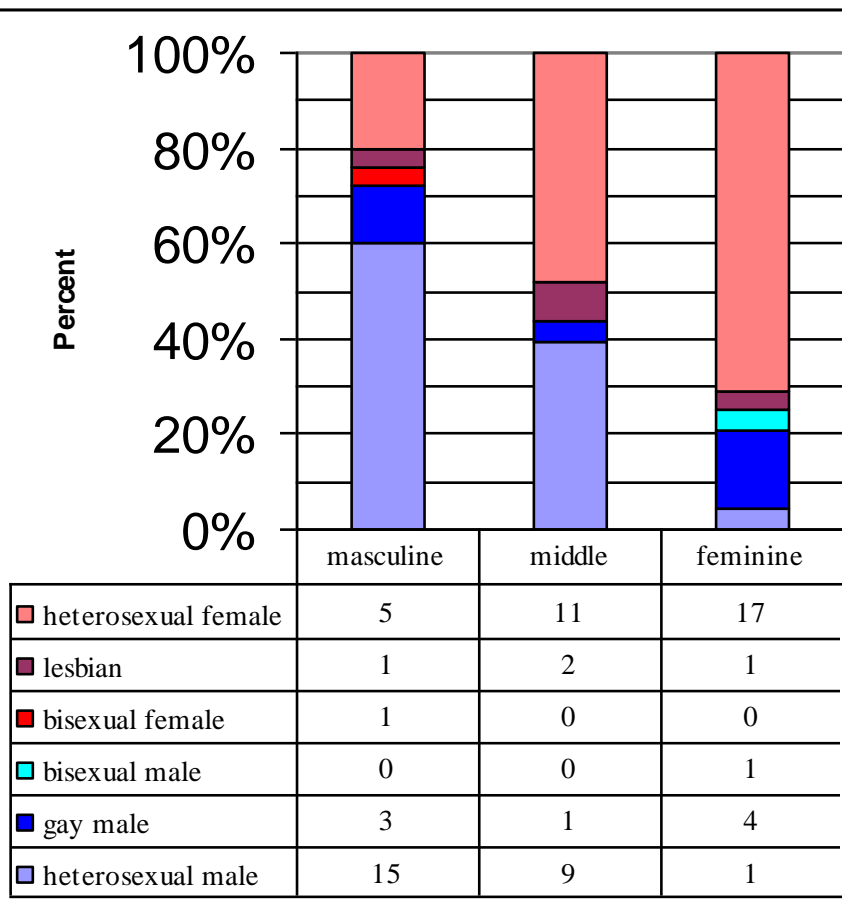

$\square$ heterosexual female

$\square$ lesbian

$\square$ bisexual female

$\square$ bisexual male

gay male

$\square$ heterosexual male

BSRI Category 
FIGURE 4 - Box plots showing differences of Interpersonal Distance between dyads of different Bem Sex Role Inventory (BSRI) categories.

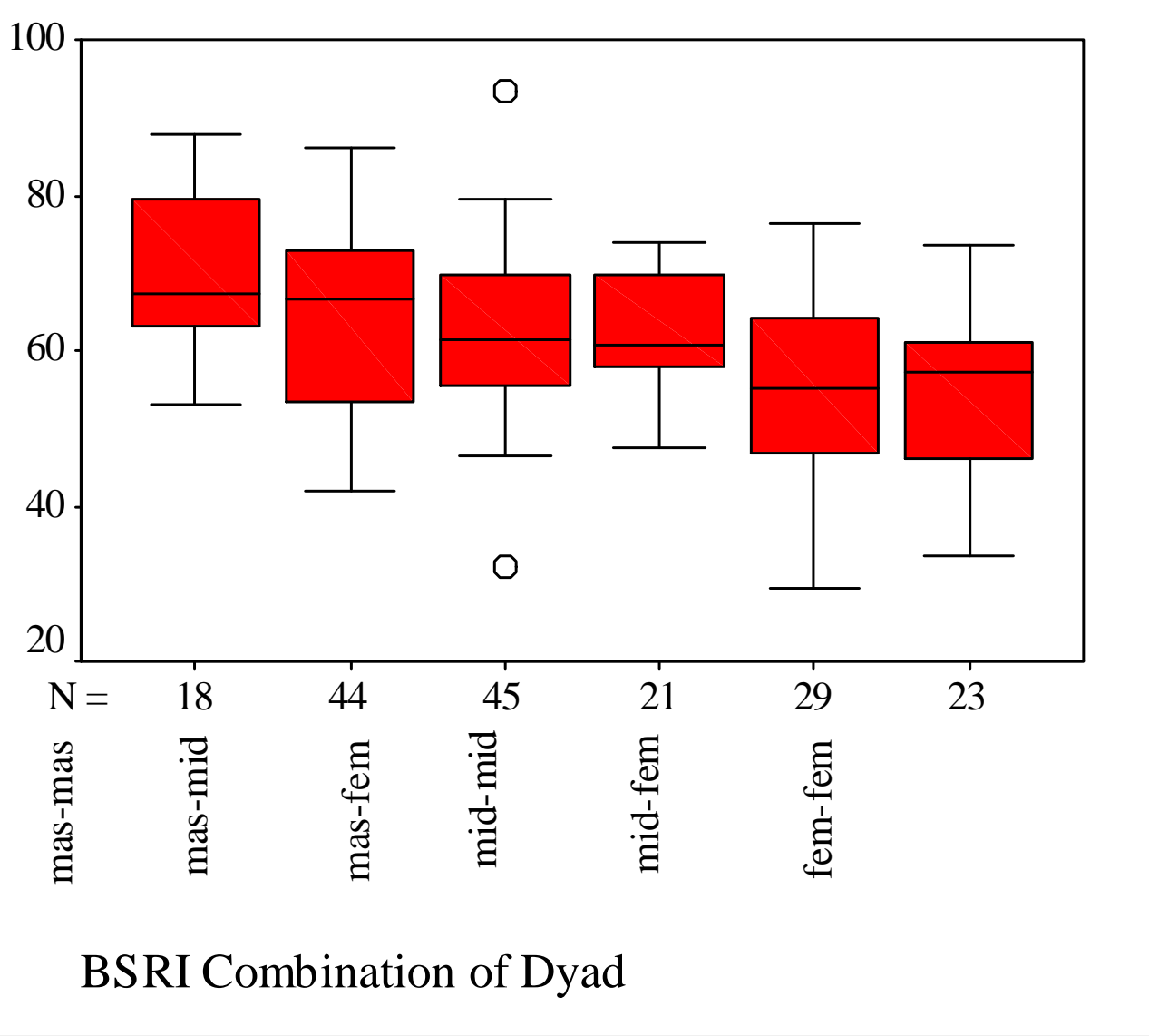


TABLE 1

ORDER OF DYAD INTERACTION

\begin{tabular}{|l|c|c|c|}
\hline Station & A & B & C \\
\hline \multirow{4}{*}{ Participants } & $1 / 2$ & $3 / 4$ & $5 / 6$ \\
\cline { 2 - 4 } & $3 / 5$ & $2 / 6$ & $1 / 4$ \\
\cline { 2 - 4 } & $1 / 3$ & $4 / 6$ & $2 / 5$ \\
\cline { 2 - 4 } & $1 / 6$ & $5 / 4$ & $2 / 3$ \\
\cline { 2 - 4 } & $2 / 4$ & $3 / 6$ & $1 / 5$ \\
\hline
\end{tabular}


TABLE 2

Descriptive Statistics for the Interpersonal Distance Measurements for Dyads within each Variable Group

\begin{tabular}{|l|r|r|r|}
\hline SEX & $\begin{array}{c}\text { Male- } \\
\text { Male }\end{array}$ & $\begin{array}{c}\text { Male- } \\
\text { Female }\end{array}$ & $\begin{array}{c}\text { Female- } \\
\text { Female }\end{array}$ \\
\hline Mean & 63.41 & 62.80 & 56.33 \\
\hline s.d. & 9.66 & 12.20 & 11.18 \\
\hline minimum & 45.42 & 29.36 & 32.08 \\
\hline maximum & 84.61 & 93.35 & 76.20 \\
\hline
\end{tabular}

\begin{tabular}{|c|c|c|c|c|c|c|}
\hline BSRI & $\begin{array}{l}\text { Masculin } \\
\text { e- } \\
\text { Masculin } \\
e\end{array}$ & $\begin{array}{c}\text { Masculine } \\
- \\
\text { Intermedia } \\
\text { te }\end{array}$ & $\begin{array}{l}\text { Masculine- } \\
\text { Feminine }\end{array}$ & $\begin{array}{l}\text { Intermedi } \\
\text { ate- } \\
\text { Intermedi } \\
\text { ate }\end{array}$ & $\begin{array}{l}\text { Intermedia } \\
\text { te- } \\
\text { Feminine }\end{array}$ & $\begin{array}{c}\text { Feminine } \\
- \\
\text { Feminine }\end{array}$ \\
\hline $\mathrm{M}$ & 70.00 & 64.90 & & 62.25 & & 53.40 \\
\hline s.d. & 9.75 & 11.61 & & 7.73 & 39 & 11.74 \\
\hline minimum & 53.04 & 41.91 & 32 & 47.63 & 29.36 & 33.50 \\
\hline maximum & 87.78 & 86.06 & 93.35 & 73.99 & 76.20 & 73.66 \\
\hline
\end{tabular}

\begin{tabular}{|l|r|r|r|r|r|r|r|}
\hline & $\begin{array}{c}\text { Hetero } \\
\text { Male - } \\
\text { Hetero } \\
\text { Male }\end{array}$ & $\begin{array}{c}\text { Hetero } \\
\text { Male }- \\
\text { Gay }\end{array}$ & $\begin{array}{c}\text { Hetero } \\
\text { Male - } \\
\text { Lesbian }\end{array}$ & $\begin{array}{c}\text { Hetero } \\
\text { Male - } \\
\text { Bisexual }\end{array}$ & $\begin{array}{c}\text { Hetero } \\
\text { Male - } \\
\text { Hetero } \\
\text { Female }\end{array}$ & $\begin{array}{c}\text { Gay - } \\
\text { Gay }\end{array}$ & $\begin{array}{c}\text { Gay - } \\
\text { Lesbian }\end{array}$ \\
\hline Mean & 63.56 & 63.30 & 71.30 & 64.69 & 63.55 & 59.69 & 60.57 \\
\hline s.d. & 8.88 & 12.01 & 10.23 & 1.91 & 11.22 &. & 7.92 \\
\hline minimum & 46.35 & 45.42 & 51.92 & 62.23 & 35.08 & 59.69 & 55.58 \\
\hline maximum & 76.20 & 84.61 & 82.07 & 66.68 & 93.35 & 59.69 & 72.39 \\
\hline
\end{tabular}

\begin{tabular}{|l|r|r|r|r|r|r|}
\hline $\begin{array}{l}\text { Sexuality } \\
\text { Cont }\end{array}$ & $\begin{array}{c}\text { Gay - } \\
\text { Bisexual }\end{array}$ & $\begin{array}{c}\text { Gay - } \\
\text { Hetero } \\
\text { female }\end{array}$ & $\begin{array}{c}\text { Lesbian - } \\
\text { Lesbian }\end{array}$ & $\begin{array}{c}\text { Lesbian - } \\
\text { Hetero } \\
\text { Female }\end{array}$ & $\begin{array}{c}\text { Bisexual - } \\
\text { Hetero } \\
\text { female }\end{array}$ & $\begin{array}{c}\text { Hetero } \\
\text { Female - } \\
\text { Hetero } \\
\text { Female }\end{array}$ \\
\hline Mean & 66.19 & 57.11 & 76.20 & 65.88 & 60.20 & 54.02 \\
\hline s.d. &. & 15.68 &. & 5.26 & 5.08 & 10.95 \\
\hline minimum & 66.19 & 29.36 & 76.20 & 59.69 & 53.19 & 32.08 \\
\hline maximum & 66.19 & 87.78 & 76.20 & 71.91 & 67.16 & 74.63 \\
\hline
\end{tabular}


TABLE 3

CORRELATIONS BETWEEN INTERPERSONAL DISTANCE AND THE THREE GENDER RELATED VARIABLES

\begin{tabular}{|c|c|c|c|c|}
\hline Spearman's rho & $\begin{array}{c}\text { Distance in } \\
\mathbf{c m}\end{array}$ & Sex & Sexuality & BSRI \\
\hline Distance in cm & 1.00 & $-.21^{* \star}$ & $-.29^{\star \star}$ & $-.39 * *$ \\
\hline Sex & $-.21 * *$ & 1.00 & $.91^{\star *}$ & $.41^{\star *}$ \\
\hline Sexuality & $-.29 * *$ & $.91^{* *}$ & 1.00 & $.52^{\star *}$ \\
\hline BSRI & $-.39 * *$ & $.41^{* *}$ & $.52^{\star \star}$ & 1.00 \\
\hline
\end{tabular}


TABLE 4

DYAD GENDER ROLE COMBINATIONS AND SIGNIFICANT DIFFERENCES IN INTERPERSONAL

DIFFERENCES BETWEEN THESE GROUPS

\begin{tabular}{|c|c|c|c|c|c|c|}
\hline & /masculine & $\begin{array}{l}\text { masculine } \\
\text { /Intermedi } \\
\text { ate }\end{array}$ & $\begin{array}{l}\text { masculine/ } \\
\text { feminine }\end{array}$ & $\begin{array}{c}\text { Intermedi } \\
\text { ate } \\
\text { /Interme } \\
\text { diate }\end{array}$ & $\begin{array}{c}\text { Intermedi } \\
\text { ate } \\
\text { /feminine }\end{array}$ & $\begin{array}{l}\text { feminine } \\
\text { /feminine }\end{array}$ \\
\hline masculine/masculine & - & - & - & - & ** & ** \\
\hline masculine/Intermedia & - & - & - & - & * & * \\
\hline masculine/feminine & - & - & - & - & - & * \\
\hline $\begin{array}{l}\text { Intermediate/Interme } \\
\text { diate }\end{array}$ & - & - & - & - & - & - \\
\hline Intermediate/feminine & ** & * & - & - & - & - \\
\hline feminine/feminine & ** & * & * & - & - & - \\
\hline
\end{tabular}

